\title{
Proximal Interphalangeal Joint 4 of the Foot
}

National Cancer Institute

\section{Source}

National Cancer Institute. Proximal Interphalangeal Joint 4 of the Foot. NCI Thesaurus.

Code C114207.

A ginglymoid (hinge) synovial joint within the fourth digit of the foot connecting the proximal and middle phalanges. 